
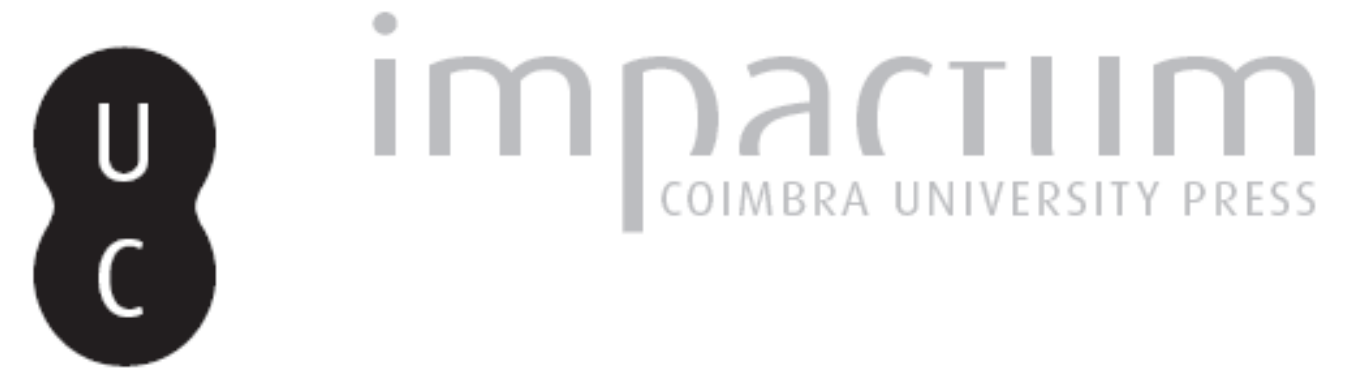

\title{
A realidade da literatura europeia
}

Autor(es): $\quad$ Gigliucci, Roberto

Publicado por: Imprensa da Universidade de Coimbra

URL persistente:

URI:http://hdl.handle.net/10316.2/42655

DOI:

DOI:https://doi.org/10.14195/0870-8584_2_20

Accessed : $\quad$ 26-Apr-2023 10:54:28

A navegação consulta e descarregamento dos títulos inseridos nas Bibliotecas Digitais UC Digitalis, UC Pombalina e UC Impactum, pressupõem a aceitação plena e sem reservas dos Termos e Condições de Uso destas Bibliotecas Digitais, disponíveis em https://digitalis.uc.pt/pt-pt/termos.

Conforme exposto nos referidos Termos e Condições de Uso, o descarregamento de títulos de acesso restrito requer uma licença válida de autorização devendo o utilizador aceder ao(s) documento(s) a partir de um endereço de IP da instituição detentora da supramencionada licença.

Ao utilizador é apenas permitido o descarregamento para uso pessoal, pelo que o emprego do(s) título(s) descarregado(s) para outro fim, designadamente comercial, carece de autorização do respetivo autor ou editor da obra.

Na medida em que todas as obras da UC Digitalis se encontram protegidas pelo Código do Direito de Autor e Direitos Conexos e demais legislação aplicável, toda a cópia, parcial ou total, deste documento, nos casos em que é legalmente admitida, deverá conter ou fazer-se acompanhar por este aviso.

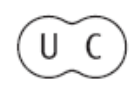




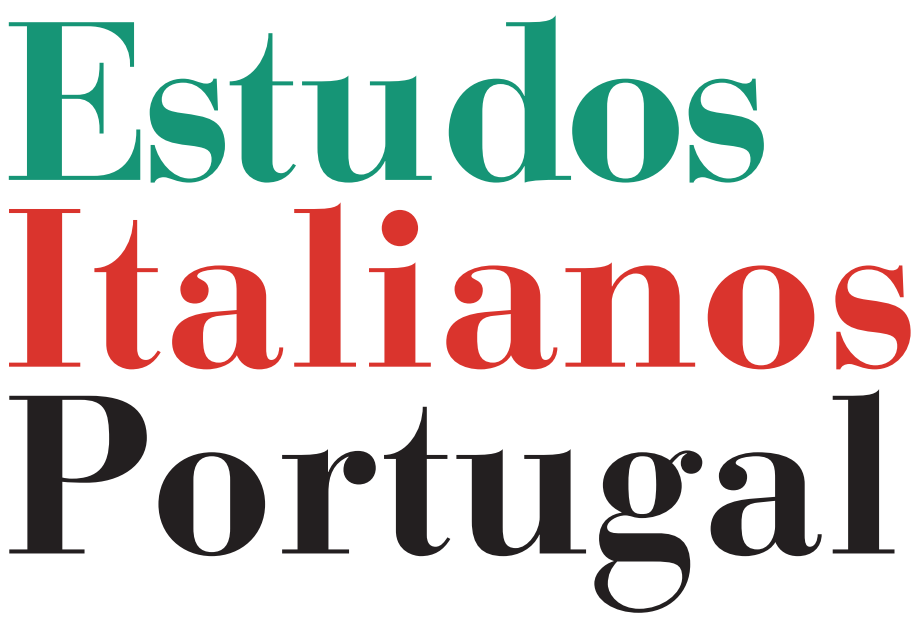

Instituto

Italiano

de Cultura

de Lisboa

Nova Série

$\mathbf{N}^{\mathbf{0}} 2$ 


\section{A REALIDADE DA LITERATURA EUROPEIA}

Roberto Gigliucci ${ }^{\star}$

"Ma i fatti ci ostano"

G. MAZZINI

SOBRE IDENTIDADE NACIONAL, também a literatura tem uma palavra a dizer. E tem vindo a dizê-la, ao longo dos séculos, ora de modo desesperado, ora confiante, ora turbulento, desde a época comunal até à da unificação e até àquela modernidade sanguinosa do século XX, que o recente livro de Alain Badiou, $\mathrm{Il} \mathrm{secolo}^{1}$, um livro de fazer gelar, põe à frente dos nossos olhos. Aliás, sobre identidade nacional, em âmbito histórico-literário, não falta bibliografia recente. É precisamente sobre a Itália dos letrados, aquela Itália que foi sonhada e parcialmente edificada pelos letrados, o belo ensaio de Stefano Jossa para o qual remetemos, L'Italia letteraria ${ }^{2}$.

Partimos das premissas do livro de Jossa para reflectir sobre a necessidade, ou não, de insistir sobre as identidades nacionais, quase como se fossem formas a priori, modelos que não se podem mudar. Jossa, nas primeiras páginas do volume, escreve: "la letteratura è trasformazione, dialogo, continuità

* Roberto Gigliucci é Investigador de literatura italiana na Universidade de Roma, La Sapienza. Dedica-se ao estudo da lírica do Renascimento e do Barroco, ao século XX, ao expressionismo e à ideologia. Trabalhou sobre o petrarquismo, no plano filológico e interpretativo, Torquato Tasso e Giovan Battista Pigna. Editou criticamente Petrarca e Lodovico Domenichi. Acaba de editar o ensaio Realismo metafisico e Montale.

1 Milano, Feltrinelli, 2006.

2 Bologna, il Mulino, 2006. 
e confronto, creazione di mondo e domanda sul mondo". Poderá parecer paradoxal citar um ensaio sobre a identidade nacional italiana como convite a uma superação dessa mesma identidade, a partir do plano da literatura (leia-se, da arte em geral). Mas não é paradoxal, pelo contrário, recomeçar precisamente a partir da literatura, das suas vivências, dos seus estatutos e da sua didáctica, para compreender se existe um regime possível de liberdade e portanto de construções identitárias mais vastas, múltiplas e compresentes. Era Auerbach quem recordava, num ensaio de 1952, definido por Claudio Guillén ${ }^{3}$ como "saggiamente malinconico", que "Jedenfalls aber ist unsere philologische Heimat die Erde: die Nation kann es nicht mehr sein" ${ }^{4}$. A nossa pátria filológica é a terra. "La letteratura", acrescenta Guillén, "ci situa repentinamente nella sopranazionalità. Questo è l'ambito reale, quello che c'è, che esiste, per il lettore, o l'ascoltatore e lo spettatore di altre arti" ${ }^{5}$.

Trata-se de verificar se a definição histórico-formal de um fenómeno italiano se faz mais completa e precisa quando é projectada no contexto europeu. Da Itália à Europa e vice-versa, em síntese. Mas então, porque não fazer história literária europeia directamente? Chegados a este ponto, parece ser cada vez mais urgente ${ }^{6}$. E os factos, como escrevia o

3 Claudio Guillén, L'uno e il molteplice. Introduzione alla letteratura comparata [1985], Bologna, il Mulino, 1992, pp. 465 ss.

4 "Em todo o caso, porém, a nossa pátria filológica é a terra: a nação deixou de o poder ser". Erich Auerbach, Philologie der Weltliteratur. Filologia della letteratura mondiale, Castel Maggiore (Bo), Book Editore, 2006.

5 Guillén, L'uno e il molteplice, pp. 466 ss.

6 Exemplos neste sentido, sobretudo franceses, são citados por Franca Sinopoli, Il mito della letteratura europea, Roma, Meltemi, 1999, p. 61 e passim, referência bibliográfica fundamental. Algumas indicações recentes e de carácter sumário sobre a relação entre a Itália e a Europa literária: La cultura letteraria italiana e l'identità europea, Roma, Accademia Nazionale dei Lincei, 2001; Letteratura italiana, letterature europee, a cura di Guido Baldassarri e Silvana Tamiozzo, Roma, Bulzoni, 2004; Il Mediterraneo. Una rete interletteraria, a cura di Dionýz Durišin e Armando 
jovem Mazzini ${ }^{7}$, são obstáculo, cada vez mais, a um nacionalismo literário radical. Os factos são a realidade da Europa, também em âmbito literário.

Exemplo: o petrarquismo. Fenómeno italiano que parece monolítico é, bem pelo contrário, fenómeno plural. A análise amplia-se, pois, ao contexto europeu, mas sem limitações: as várias experiências, portuguesa, croata, polaca e assim sucessivamente, integram-se perfeitamente nessa ideia e são esclarecedoras. Assim, assinala-se a experiência do congresso de Varsávia sobre Petrarca e l'unità della cultura europea, organizado por Piotr Salwa (cujas actas acabam de ser publicadas $)^{8}$, mas também, do lado oposto do Continente, o simpósio, Petrarca 700 anos realizado em Coimbra e coordenado por Rita Marnoto9: esta é a Europa do petrarquismo, ou seja, da poesia, desde os países de Leste ao Atlântico, e é esta a literatura europeia que devemos explorar para fazer história da literatura nacional. No fim, verificaremos que a complexidade do petrarquismo italiano, quase surpreendente, é na realidade perfeitamente coerente ao nível europeu multinacional.

Desde os volumes de Antèro Meozzi ${ }^{10}$ acerca do petrarquismo europeu, tão doutos quanto irritantes, até à antologia BUR de Anselmi e dos seus colaboradores ${ }^{11}$, correram cerca de setenta anos, e não me parece que em Itália se tenha

Gnisci, Roma, Bulzoni, 2000; Perché la letteratura?, a cura di Raffaele Morabito, Manziana, Vecchiarelli, 2006; Italia e Europa: dalla cultura nazionale all'interculturalismo, Firenze, Cesati, 2006, e, em particular, Francesco Orlando, L'altro che è in noi. Arte e nazionalità, Torino, Bollati Boringhieri, 1996.

7 D'una letteratura europea, 1829, apud Sinopoli, Il mito della letteratura europea, pp. 93 ss. (p. 97).

\footnotetext{
8 Petrarca e l'unità della cultura europea, Warszawa, Semper, 2005.

9 Petrarca 700 anos, Coimbra, Instituto de Estudos Italianos da FLUC, 2005.

${ }_{10}$ Vd., por exemplo, Il petrarchismo europeo (Secolo XVI), Pisa, Vallerini, 1934.

11 Lirici europei del Cinquecento, Milano, Rizzoli, 2004.
} 
produzido uma bibliografia forte sobre o petrarquismo europeu. Os trabalhos de Meozzi encontravam-se terrivelmente viciados pelo nacionalismo fascista de um autor que procurava, por toda a Europa, sinais triunfalistas de um italianesimo, da influência civilizadora da cultura italiana. Não obstante, eram tesouros de informação e de erudição tantas vezes inteligentes, sendo que tivemos de esperar décadas, muito possivelmente, para dispormos de materiais complexos e bem distribuídos, até chegarmos ao recente congresso de Bolonha sobre o petrarquismo, Il Petrarchismo: un modello di poesia per l'Europa, que privilegia a perspectiva europeia, e cujas actas acabam de ser publicadas ${ }^{12}$. Como quer que seja, diga-se que o estudo do petrarquismo europeu faz bem à inteligibilidade da casa mãe, da Itália. Verifica-se tradicionalmente na Europa, por exemplo, uma série de desvios à ortodoxia petrarquista, como seja: a hibridez entre imitar Petrarca e imitar os clássicos antigos; uma maior sensualidade da relação amorosa; a variante do amor matrimonial; a filtragem de Petrarca através dos petrarquistas modernos, primeiro os cortesãos dos séculos XV e XVI, depois, eventualmente, os que se encontram nas antologias de rime di diversi na segunda metade do século XVI. Pois bem, regressando então ao mare magnum do petrarquismo italiano, encontramos, mais ou menos, todos estes elementos num petrarquismo verdadeiramente plural ${ }^{13}$, onde o modelo absoluto de ortodoxia, que é o de Bembo, nem pelas suas próprias Rime é respeitado. Redescobrimos, assim, a importância determinante das antologias de meados do século (uma das grandes novidades

121 Petrarchismo. Un modello di poesia per l'Europa, a cura di Floriana Calitti, Loredana Chines, Roberto Gigliucci, Roma, Bulzoni, 2006, 2 vol.

13 Reenvio, por questões de brevidade, para os meus contributos mais recentes: "Petrarquismo plural e petrarquismo de koine", Petrarca 700 anos, pp. 121 -129 (em italiano, "Appunti sul petrarchismo plurale", Italianistica, 34, 2, 2005, pp. 71-75); "Perspectivas e sucessos dos estudos sobre o petrarquismo", Estudos Italianos em Portugal, n. s., 1, 2006, pp. 113-127. 
dos estudos mais recentes, embora precedida, é certo, pelas pesquisas pioneiras de Quondam) ${ }^{14}$, aprofundamos a importância das rimas uxórias de Rota, Giustinian, Coppetta Beccuti etc.; seguimos um filão de petrarquismo sensual, de basiis, que, partindo de Ariosto, atravessa o século XVI com Muzzarelli (I dolci basci replicati spesso), em particular com Pigna (o tour de force de composições sobre beijos no manuscrito Corsini $)^{15}$, e chega a Marino. Sobretudo, e isto é o dado mais relevante, descobre-se que no petrarquismo plural italiano a hibridação de Petrarca com os clássicos latinos e gregos é património de uma linha fortíssima, às vezes numa atitude abertamente polémica (Brocardo e Bernardo Tasso que se coloca sob o seu magistério), mas que também pode ser uma praxe imitativa natural, envolvendo o próprio Bembo e, por trás dele, o próprio fundador do código, $\mathrm{Pe}-$ trarca: eis então a refinada poesia de um Alamanni, de um Varchi, de um Caro, de um Raineri, de um Molza, ou de um minore altamente emblemático como Domenichi. Até chegar ao génio de Torquato Tasso, em cujas Rime há tudo aquilo que, na Europa daqueles anos e dos que se lhe seguem imediatamente, vai sendo afinado.

E se pensarmos no chamado marinismo em sentido europeu, também bate certo? Sem dúvida. Compreender e reintegrar através de uma avaliação séria a lírica barroca italiana só se pode fazer à luz do Barroco europeu. Descobre-se que talvez não sejam tanto o vazio e a imoralidade a formarem a identidade da poesia barroca, como a nova relação com a realidade e portanto a participação na genealogia do moderno. Paradoxalmente, os testemunhos da interacção entre o mari-

14 Amedeo Quondam, Petrarchismo mediato. Per una critica della forma "antologia”, Roma, Bulzoni, 1974.

$15 \mathrm{Vd}$., de quem ecreve, Giù verso l'alto. Luoghi e dintorni tassiani, Manziana, Vecchiarelli, 2004, pp. 154 ss. Quanto a informações bibliográficas sobre os poetas citados, reenvio para La lirica rinascimentale, a cura di R. Gigliucci, introduzione di Jacqueline Risset, Roma, Istituto Poligrafico e Zecca dello Stato, 2000. 
nismo italiano e as experiências feitas nas pontas da Europa podem ser elucidativas para a compreensão do significado e dos limites do modelo que é oferecido pelo poeta do Adone. Penso também na Polónia: ao ler os estudos de Luigi Marinelli sobre a lírica barroca polaca ${ }^{16}$ ou o livro de Alina Nowicka-Jezowa sobre Morsztyn e Marino: un dialogo poetico dell'Europa barocca ${ }^{17}$ ou ainda o sagaz livrinho de Jon Snyder sobre a Estetica del Barocco ${ }^{18}$ na Europa, que nos recorda, uma vez mais, a primazia do jesuíta polaco Kazimiersk Sarbiewski quanto à teoria setecentista do conceptismo, ao ler estes ensaios e tantos outros, dizia, aprendem-se coisas que não são de somenos acerca das vergonhas da nossa casa. E a vergonha passa ${ }^{19} \ldots$

Além disso, como é possível continuar a ler a nossa poesia barroca sem ter em consideração o nascimento de uma poesia moderna metafísica, que do reino dos emblemas absolutos regressa à empíria para depois a transcender de modo conceptual ou sublimante, apesar de cruzar os seus aspectos acidentais mais rugosos ou singulares ${ }^{20}$ ? Como é possível não ver que o paradoxal (mas não muito) realismo barroco, incunábulo do moderno, diz respeito não só a Caravaggio e Bacon, a Shakespeare e Cervantes, a Donne e Lope de Vega, a Théophile de Viau e Quevedo e mais tarde a Locke e a Johann Christian Günther, e assim por diante, mas a toda uma complexa sequência de vozes, situadas, para dizer dois

16 Cito apenas um, fundamental: G.Marino / Anonimo, La Novelletta / Bajka. La "Psiche" polacca. Migrazioni del IV canto dell' "Adone", a cura di Luigi Marinelli, Parma, Archivio Barocco, 1992.

17 Roma, il Calamo, 2001.

18 Bologna, il Mulino, 2005.

19 Como ensina Amedeo Quondam, "Il Barocco e la Letteratura. Genealogie del mito della decadenza italiana”, I capricci di Proteo. Percorsi e linguaggi del Barocco, Roma, Salerno, 2002, pp. 111-175.

${ }^{20}$ Seja-me perdoado um ulterior auto-reenvio, Realismo metafisico e Montale, Roma, Editori Riuniti, 2007. 
nomes, entre Cesare Rinaldi e Ciro di Pers. Desta feita, ao díptico nacional Marino-Chiabrera, os dois fogos do Barroco emergente, podemos juntar o de Marino-Góngora para compreender um contraste exemplar no grande palco europeu: por um lado, a experiência poética oceânica, que segue as pegadas de Nonnos, Ovídio e funda de novo o modelo totalizante-digressivo, ancorado na descoberta da natureza como maravilha e mito; por outro lado, o poema da crase metafórica, a germinação, historicamente paradigmática, da poesia da contracção absoluta, a concentração e o decorrente obscurisme, única sumptuosa e desesperada forma de interpretação do real (por exemplo, uma festa campestre nas Soledades). De resto, também quanto ao século precedente não consigo não acreditar que a leitura paralela de Tasso e de Camões não seja fundamental para perceber melhor a obra de ambos, que teve por fruto os dois maiores poemas épicos do Renascimento. E assim a importância europeia da Strage degli innocenti de Marino é um dado cuja documentação não pode deixar de incidir sobre o valor daquele produto italiano. Mas não será o caso de recordar, a quem me lê, coisas bem sabidas. Só uma ulterior reflexão: se foi sob o nome de Gôngora que se reuniu a geração de 27 , que inclui os maiores poetas espanhóis do século XX, em Itália nenhum poeta lírico do século XX pensou tomar como referência Marino e os marinistas. Mais do que isso, talvez pudesse pensar nesse mesmo Gôngora, quem sabe cruzado com Mallarmé, como para um certo Ungaretti, ou com a metafisica inglesa filtrada por Eliot e assim sucessivamente. Que significa isto, historicamente? Só através de uma historiografia sinergética nacional e internacional poderíamos responder.

Mas pensemos no tragicómico, no seu aspecto técnico e na sua complexidade categorial. Trata-se de um outro sinal, entre os séculos XVI e XVII, do nascimento de uma modernidade rica, ambígua e contraditória, fonte de espanto e desconcerto, além de técnica para satisfazer os gostos do público. 
Poucos anos separam o Compendio de Guarini do manifesto de Lope de Vega, L'arte nuevo de hacer comedias en este tiempo, cujas motivações e cujas novidades são em boa parte comuns. Séculos dividem os dois textos, que acabaram de ser evocados, do romance de Manzoni e do Cromwell de Victor Hugo, mas pelo meio há a história europeia do tragicómico que chega, quase diria teleologicamente (passe a heresia), ao Novecento de Pirandello e ao Modernismo ocidental.

Ainda mais. O caso de um poeta cuja recepção, no estrangeiro, não captou a sua grandeza, Pascoli, pode ser emblemático, ao mostrar como a avaliação histórico-poética de um autor é mais madura quando aberta ao plano internacional. É colocando Pascoli no quadro do chamado decadentismo que se afere a originalidade do seu contributo, à diferença do sonoroso D'Annunzio. Aquela poesia latina e convivial de Pascoli é, em particular, vertiginosamente europeia, porquanto oferece uma forma de classicismo mediânico, fantasmático e assombradamente fúnebre, a colocar, entre as mais avançadas e complexas, na órbita daquele gosto decadente pelo antigo, revivido em regime de inquietude estrutural.

Outros exemplos poderiam ser apresentados. O mais clamoroso é o do Romantismo, acerca do qual Pino Fasano nos ensinou tudo ${ }^{21}$ e a cuja memória dedico este meu modestíssimo contributo. Também se pode evocar o significado europeu das obras latinas de Petrarca e de Boccaccio, que bem fazem pensar quem não considere o De remediis ou o De casibus obras-primas e paradigmas de uma cultura e de uma literatura de longa duração e de longa tradição. O De casibus representa, em especial, um modelo de tragicidade que se expande como uma mancha de ólio, até chegar - e não importa ao caso se por influência directa, indirecta ou indefinível - a uma obra-prima como Les tragiques de Agrippa D’Aubigné.

21 Vd. ultimamente, L'Europa romantica, Firenze, Le Monnier, 2004. 
E para quem estuda o século XX, este ponto de vista é mesmo uma obrigação. No fundo, Curtius e Auerbach ensinaram-nos mais do que Croce, note-se. Quero dizer, ensinaram-nos a nós, italianistas. Os riscos de um enquadramento clássico auto-referencial, imperialístico e colonialístico, foram postos em relevo, obviamente, pela autoconsciência comparatística moderna, veja-se só, a partir de Wellek ${ }^{22}$. Todavia, para os séculos da euro-autonomia, ou seja, até ao século XVIII grosso modo, não existe um perigo de eurocentrismo ideológico que desoriente a pesquisa. $O$ eurocentrismo surge e desenvolve-se, perniciosamente, quando começa a decair o euro-isolamento.

Além disso, numa comunidade literária como a Europa que vai da Idade Média à Modernidade os dados intraculturais genéticos são susceptíveis de serem simplesmente definidos como intertextualidade e, por conseguinte, praxe quotidiana e obrigatória dos estudos literários também nacionais, ao passo que os dados intraculturais poligenéticos serão igualmente relevantes num quadro de interdiscursividade e de capacidade da comunidade literária europeia.

Se se pretende liquidar a italianística na comparatística? De forma alguma, e muito menos hoje, que a comparatística se volta sobretudo para pesquisas interculturais, conforme o veio a ilustrar magistralmente, já desde 1989, Earl Miner ${ }^{23}$. Aliás, a verdadeira comparação só surte, provavelmente, num regime de poligénese intercultural (no eixo este / oeste do mundo, por exemplo), de forma a evidenciar constantes e diferenças antropológico-literárias. De outra forma, o que se tem é intertextualidade, e que essa intertextualidade seja

22 Vd. Armando Gnisci, Franca Sinopoli, Manuale storico di letteratura comparata, Roma, Meltemi, 1997, pp. 93 ss. Inúmeros seriam os reenvios a contributos de Armando Gnisci sobre interculturalidade e comparatística poscolonial; evoco, mais recentemente, o belo livro, Mondializzare la mente. Via della Decolonizzazione europea n. 3, Isernia, Cosmo Iannone, 2006.

23 Gnisci-Sinopoli, Manuale storico di letteratura comparata, pp. 145 ss. 
nacional ou internacional, homolinguística ou interlinguística, não muda muito.

A língua, eis um outro problema. Pede-se ao italianista que conheça todas as línguas faladas da Europa? Obviamente que não, seria uma tolice. A literatura tem esta grande prerrogativa, a de possuir, paradoxalmente, uma língua única, a da tradução. A feliz indicação é de Franca Sinopoli, a quem agradeço. O estudo histórico da tradução é, na actualidade, parte integrante da historiografia literária. Além disso, nós vivemos de literatura, não de italianística. Todos nós, tanto Dante como Montale, como eu que falo para vós. Todos lemos Tolstoi em italiano, Gombrowicz, Schulz e também Shakespeare e Milton, e talvez Tácito e Rabelais. Releia-se Mann, o ensaio de 1925 sobre o cosmopolitismo. Excepcional sinceridade de um grande homem: "non sono per nulla un cosmopolita, sono tutt'altro che un cittadino del mondo e proprio l'opposto di un poliglotta. [...] Il mio inglese, francese e italiano sono senz'altro assai miseri [...] in tutta la mia vita sono stato un beneficiario costante delle fatiche dei traduttori. [...] Quanti di noi, francesi, inglesi o tedeschi, sono in grado di gustare nell'originale anche soltanto il Don Chisciotte? [...] lo spirito cosmopolita è qualcosa di diverso dall'abilità poliglotta e dal dilettantismo mondano. E allora che cos'è? Forse nient'altro che lo spirito della vita e della trasformazione" ${ }^{24}$. Com certeza, fala um escritor, não um filólogo. Mas nós, filólogos, ocupamo-nos de escritores, não é?

Com tudo isto, querer-se-á eliminar o estudo e o ensino da língua original? Nunca, nem por sombras. Trata-se de compreender que os sujeitos literários, os homens, sempre leram obras em tradução e portanto o circuito europeu tem uma vivacidade própria também nesta sua dimensão, a ser estudada historicamente, sempre com maior atenção. A lite-

${ }^{24}$ Sinopoli, Il mito della letteratura europea, pp. 150 ss. 
ratura é feita pelos letrados. E essa literatura é naturaliter internacional, enquanto formada a partir de textos de todas as nacionalidades. De facto, Babel é uma condenação, não é uma riqueza, como só um snob podia dizer. Se Babel é uma condenação, e não uma riqueza, a literatura é também a resposta a Babel, inesgotável, talvez em desespero de causa, mas uma resposta estrénua e constante, ao longo dos séculos. O dramático problema da multiplicidade das línguas resolve-se com a invenção das traduções. Nelas se fundamenta, tantas vezes, uma literatura nacional. É assim que se verifica que na literatura há mais liberdade do que na vida política ou civil, ou melhor, há uma antecipação das liberdades que depois tomam forma ou pelos menos se projectam na realidade histórica. Sem esquecer que a distinção literatura / realidade é fictícia: cada uma interage com a outra, participa na outra.

Convirá dizer, com mais brutalidade, que a disciplina da italianística se há-de salvar da crise se caminhar a passos largos para uma consciencialização da necessidade de estudar os fenómenos literários italianos à luz de uma perspectiva mais ampla, pelos menos europeia até aos inícios da Modernidade, e a partir daí mais amplamente mundial (do colonialismo à globalização). Não é um exagero, bem pelo contrário. Exagero, no máximo, é falar-se de uma literatura italiana, de uma literatura francesa, inglesa, etc. É óbvio, diria, que para preparar edições de textos é necessária uma competência linguística e contextual circunscrita e específica. O mesmo acontece quanto ao estudo de fenómenos pontuais, verticais, sincrónicos. Mas para historiar e interpretar a literatura (ou seja, para fazer trabalho filológico, em sentido amplo) o confim identitário nacional torna-se um limite, irreal em domínios artístico-literários.

Irreal, precisamente, irreal. Repito-o, a nossa identidade literária é feita de uma intersecção de leituras absolutamente autónomas relativamente a um cânone italianístico. Que se 
leiam em tradução italiana ou não, o certo é que, no nosso universo literário individual e depois colectivo Shakespeare é tão ou mais activo do que Tasso, Baudelaire, tão ou mais activo do que Leopardi, etc. Portanto, a literatura italiana, na formação e na produção de indivíduos e comunidades, constrói-se na intersecção de tantas literaturas, fundamentalmente europeias e mediterrânicas, até ao século XIX, também ultra-oceânicas e universais.

O novo objecto intercultural da comparatística pode-se distinguir, como tal, da perspectiva historiográfico-literária europeia, matéria de estudo, cada vez mais, de analistas das literaturas nacionais europeias. Com certeza que não queremos dar uma vassourada nos desvios intraculturais daquela comparatística mais politicamente correcta, mais intercultural... Facto é que houve uma história da literatura europeia e não a podemos ignorar. Além disso, fenómenos recentes mostram como a fisionomia político-cultural forte e unitária da Europa é um bem para o equilíbrio mundial, para a mútua atenção e para a integração. Uma Europa identitária e não isolada faz bem a um mundo interconexo e pacífico. É claro, uma Europa que não arraste, belicosa e fundamentalisticamente, origens cristãs e pseudovalores comunitários. Uma Europa moderna sem nostalgia do pior da sua história, uma Europa da literatura, ou seja, da liberdade. 